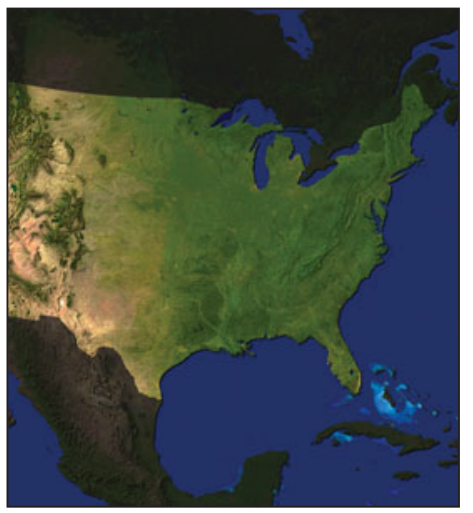

\section{Grid battery storage gets big in the States}

\section{By Prachi Patel}

Feature Editor Brian Perusse

$\mathbf{P}$ icture this: It's holiday season and days before the busiest shopping week. A retailer in a large city is about to run out of the season's hottest toy. A quick call to the local warehouse, and disaster is averted.

The retail industry could not operate without thousands of cubic meters worth of storage warehouses. Yet, the power sector, one of the biggest industries in the world, works with minimal storage. Instead, the norm is to make power plants with spare generating capacity or to build extra natural gas "peaker" plants. Utilities kick on the plants during high demandwhen air conditioners run at full blast in the summer or when lights go on at dusk. But most of the time, generating equipment sits unused or inefficiently running below maximum output. It's like having a toy factory sitting on standby to make a thousand new toys for the one day when your store shelves are empty. Or, as Brian Perusse of power company AES put it, "You need to buy a whole car when all you need is the radio."

Storing electricity on a large scale would make the grid more efficient and reliable. The idea is to run power plants at a steady level, which is more fuelefficient, store excess generated energy when grid-load is low, and use those stores when demand spikes.

More than $99 \%$ of grid storage- 127 GW according to the Electric Power Research Institute (EPRI) - is done today by pumping water into elevated reservoirs during off-peak hours and flowing it through electricitygenerating turbines when needed. But sites suitable for such pumped hydro systems are hard to come by.

Batteries, which are portable, modular, and easier to install, are increasingly attractive for grid storage. They still have high capital costs, and there is no onesize-fits-all solution to various applications that require anywhere from a few $\mathrm{kW}$ to tens of MW for times ranging between a few seconds to hours. But developers can reap benefits by matching grid application with the right technology.

As of April 2010, batteries stored 451 MW of electric power for the grid worldwide. In Japan, batteries have been connected to the grid since the early 1990s. Now the technology is cropping up at power plants and wind farms across the United States. Fairbanks, Alaska boasts the world's most powerful storage system: a bank of nickel-cadmium batteries that can provide $46 \mathrm{MW}$ for five minutes. AES has connected $72 \mathrm{MW}$ of batteries to grids in the United States and Chile. Utilities such as Duke Energy and Southern California Edison are investing in large battery systems. Flow battery-maker Primus Power is constructing a large system in California, while Xtreme Power has a fleet of advanced lead-acid battery systems in Hawaii. EPRI, meanwhile, is trying to develop industry standards for grid battery storage, which should make it easier for utilities to install battery systems in the future.

With more experience, better technologies, and bigger production scales, largescale battery storage should make more and more economic sense. "Major players are showing interest, and that makes a big difference," said Haresh Kamath, program manager for energy storage at EPRI.

Currently, developers are targeting applications that require injecting short bursts of power into the grid. These include smoothing the small variations in the grid's alternating current frequency and seamlessly integrating intermittent wind and solar power into the grid. Batteries are good for such applications because they can quickly release energy and cycle hundreds of times daily with low energy loss.

Most current projects employ advanced lead-acid and lithium-ion batteries, which are proven in portable electronics and vehicles. These technologies are improving even as newer chemistries become available, bringing down battery costs. "As costs drop over the next decade, a greater number of applications will open up," said Yet-Ming Chiang, a professor in materials science and engineering at the Massachusetts Institute of Technology.

Certain market conditions, such as geographical constraints and policy restrictions, can bolster the value of battery storage. Batteries make sense now, for instance, on islanded grids where smaller, less-efficient generators burn expensive fuel to meet peak demand, or on remote locations with unstable or poorly connected grids. This underlines why the power authority on New York's Long Island is reviewing a 400-MW project by AES. "It's really difficult to get power in and out and to build anything there," Perusse said.

In the mining region of northern Chile, meanwhile, two-dozen power plants sustain several large mines. If one of the plants or mines slips off-line, grid power can swing by hundreds of MW. To manage the swings, the government mandates operators to keep 7\% of their plant's capacity as an unsold reserve. So power generators do not get paid for all the energy they can produce, while plants run inefficiently at below-maximum capacity. Mining companies also face a cost: 
if grid frequency drops, the grid operator cuts power to mines on a rotating basis.

AES's Chilean subsidiary AES Gener thought holding reserve power in batteries would be more efficient. In late 2009, a 12-MW system containing lithium-ion batteries went into operation at a transmission substation in the Atacama Desert. The system can inject power in 200 milliseconds, as opposed to minutes for peak plants. The system's viability led AES Gener to install a 20-MW system alongside a 544-MW power plant that came online in 2011.

In Laurel Mountain, W.Va., an opportunity presented itself for adding energy storage to a wind development project. The company was building a $125 \mathrm{MW}$ wind farm, and a year-and-a-half before commercial operation, new regulations reduced the project's size to $97 \mathrm{MW}$. With the support of grid operator PJM and the local utility, AES accommodated the additional power in lithium-ion batteries that provide reserve capacity for the local grid.

EACH kW of storage capacity at Laurel Mountain cost about $\$ 900$ to install. Clean, efficient natural gas combined cycle plants cost $\$ 1400 / \mathrm{kW}$, while a simple cycle natural gas turbine costs $\$ 700$. However, said Perusse, capital cost

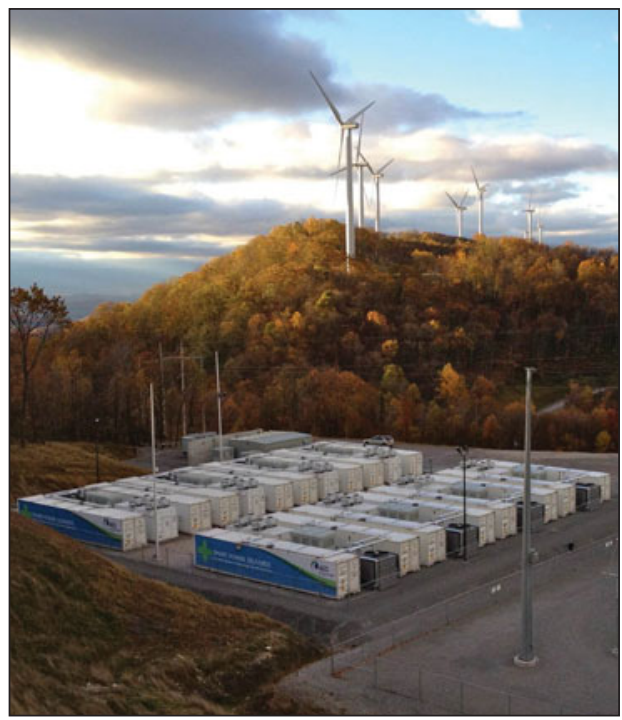

A $32 \mathrm{MW}$ fleet of batteries smooths the output from the AES Corporation's wind farm in Laurel Mountain, W.Va. Image courtesy of AES. alone does not paint a complete picture. Battery storage is more valuable because it can quickly inject the precise amount of power the grid needs, absorb excess energy on the grid, provide reserves without a minimum generation requirement, and be sited anywhere. Plus, it has no emissions and little water use.

Nevertheless, cost and lack of experience are the biggest hurdles to widespread use of battery storage, said Kamath. Utility-scale battery storage will likely follow the path of solar and wind energy. The first few installations will be expensive, but as developers gain experience and test the technology's viability, confidence should increase. Many power plant owners are testing 1-2 MW systems, but are not yet ready to invest in large commercial installations. "The utility industry is driven entirely by reliability, not cost," said Kamath. "People don't want to necessarily invest in uncertain technology, especially when that uncertain technology is a little more expensive."

Large-scale production will be key for reducing cost of batteries and other components. Until recently, battery makers were focused on the electric vehicle market. But now they are producing more batteries and are starting to configure and sell them as large grid-scale systems. "Development for electric vehicles is bringing down battery cost, and as manufacturers make more batteries, they know how to bring down cost further," Kamath said. "It's the same with power electronics. The solar industry uses the same power electronics, and as it takes off, a lot of economies of scale are applying to the storage industry."

It takes somewhere between $\$ 500$ and $\$ 2500$ to install each $\mathrm{kWh}$ of energy storage depending on battery type and application, according to EPRI. This number includes the cost of batteries, power electronics, permits, and labor. In 2010, batteries alone comprised $75 \%$ of a storage system's cost, but now they make two-thirds of the system's cost, Kamath said. The US Department of Energy's Advanced Research Projects AgencyEnergy has set a goal of $\$ 100 / \mathrm{kWh}$ for grid-scale batteries. To get to that level, said Chiang, "new battery technologies in particular have an important role to play."

This includes advanced lithium-ion battery materials. Many research groups around the world are working on highcapacity silicon-based anodes and manganese oxide-based cathodes for lithium-ion batteries, but so far these are not stable enough for vehicle or grid applications. Another area of interest is electrolytes that can operate at high voltages.

Flow batteries, a decades-old technology, are seeing a comeback. Instead of solid electrodes, flow batteries use two liquid electrolytes that react as they flow through cells. They have the advantage of quick response time, long cycle life, and tolerance to overcharging, but the energy density is lower than many portable batteries. The technology is viable but has not been widely tested. That could change with Primus Power's 25 MW modular zinc-chlorine flow-battery system being built in California's Modesto Irrigation District.

Others are developing novel battery chemistries. Boston, Mass.-based Pellion is working on magnesium-ion batteries. General Electric has opened a factory to make a new battery based on two-decades-old nickel-sodium-chloride chemistry. Pittsburgh, Pa.-based Aquion Energy is close to starting large-scale manufacture of its sodium-ion batteries. Still others, such as Axion Power, are combining lead-acid battery chemistry with electrochemical capacitors to create hybrid devices that quickly absorb and release charge.

Chiang, meanwhile, is working on a battery that uses flow battery architecture but replaces conventional aqueous solution electrolytes with suspensions of solid lithium materials, which have at least 10 times higher energy density. The design would be low-cost because it is easier to manufacture and needs fewer components than lithium-ion devices. "One thing to keep in mind is you need to address both the numerator and denominator of dollars-per-kilowatt-hour," he said. "The most interesting opportunities for batteries are going to involve both new, interesting materials science as well as innovative device design." 